\title{
GENOTYPIC CHARACTERIZATION OF VIRULENCE FACTORS IN Escherichia coli STRAINS FROM PATIENTS WITH CYSTITIS
}

Monique Ribeiro TIBA(1), Tomomasa YANO(2) \& Domingos da Silva LEITE(1)

\begin{abstract}
SUMMARY
Adhesins (P-fimbriae, S-fimbriae, type 1 fimbriae and afimbrial adhesin), toxins ( $\alpha$-hemolysin and cytotoxic necrotizing factor type 1), iron acquisition systems (aerobactin) and host defense avoidance mechanisms (capsule or lipopolysaccharide) have been shown to be prevalent in Escherichia coli strains associated with urinary tract infections. In this work, 162 Uropathogenic Escherichia coli (UPEC) strains from patients with cystitis were genotypically characterized by polymerase chain reaction (PCR) assay. We developed three multiplex PCR assays for virulence-related genes papC, papE/F, papG alleles, fimH, sfa/foc, afaE, hly, cnf-1, usp, cdtB, iucD, and kpsMTII, all of them previously identified in UPEC strains. The PCR assay results identified 158 fimH (97.5\%), $86 \mathrm{kpsMTII}$ (53.1\%), 53 papC/papEF/papG (32.7\%), 45 sfa (27.8\%), 42 iucD (25.9\%), 41 hly (25.3\%), 36 usp (22.2\%), 30 cnf-1(18.5\%) and 10 afa $(6.2 \%)$ strains. No strain was positive for $c d t B$. In this work, we also demonstrated that adhesins may be multiple within a single strain and that several virulence genes can occur combined in association.
\end{abstract}

KEYWORDS: Uropathogenic Escherichia coli (UPEC); Polymerase chain reaction (PCR); Virulence factor (VF).

\section{INTRODUCTION}

Urinary Tract Infections (UTIs), including cystitis and pyelonephritis, are among the most frequent human extraintestinal infections. Escherichia coli is the major causative agent, and it also is the predominant facultative member of the normal human intestinal flora ${ }^{23}$. This agent primary of UTIs accounts for greater than $80 \%$ of these infections. The bladder is the primary site of infection in about $95 \%$ of all UTIs ${ }^{23}$. In most cases, uropathogenic clones are selected from the fecal flora and colonize the vaginal and periurethral tissue, and infected the urinary tract by the ascending manner.

Classification of UTIs depends on the part of the urinary tract which is colonized (lower or upper urinary tract), as well as on the individual predisposition. Cystitis (lower UTI) is characterized by pelvic discomfort, especially pre - and immediately post void, frequent or urgent voiding and suprapubic pain. Acute pyelonephritis (upper UTI) is, most of the times, a more serious problem and is clinically identified by the fever, flank pain, nausea and, sometimes, vomiting ${ }^{19,22,23}$.

Uropathogenic Escherichia coli (UPEC) isolates are a genetically heterogeneous group that exhibit several virulence factors associated with colonization and persistence of the bacteria in the urinary tract. The virulent strains of UPEC that cause cystitis typically produce, at least, one adhesion system. Adhesins can also contribute to virulence, promoting colonization, invasion and replication within uroepithelial cells ${ }^{22,23}$. Besides bacterial adherence, several virulence factors may contribute to the pathogenicity of UPEC, facilitating the ability to adhere specifically to uroepithelial cells and the expression of other bacterial products to host tissues such as toxins, iron acquisition systems and host defense avoidance mechanisms ${ }^{26}$.

Virulence factors (VFs) associated with UPEC include adhesins (P fimbriae, type 1 fimbriae, $\mathrm{S}$ and $\mathrm{F} 1 \mathrm{C}$ fimbriae, afimbrial adhesin), toxins (hemolysin, and cytotoxic necrotizing factor), siderophores (the aerobactin system) and polysaccharide coatings (group II capsules) ${ }^{1,29}$. Recently, a new urovirulence factor gene, which was more frequently found in UPEC strains, was reported. This gene encoding a protein designated usp (uropathogenic-specific protein) was demonstrated significantly enhancing the infectivity of E. coli in the mouse UTI model ${ }^{15,18,28}$.

The aim of this study was to detect the virulence genes of E.coli strains isolated from patients with clinical signs of cystitis in Brazil. PCR method was used for this purpose.

\section{MATERIAL AND METHODS}

Bacterial strains: A total of $162 \mathrm{E}$. coli strains collected in the mid-1990s, were isolated from each woman patient with recurrent UTI, attended at the Ambulatory sector of Medical School Hospital of the

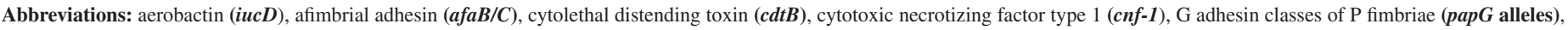

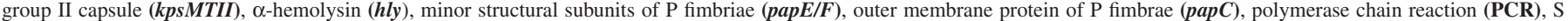
fimbriae (sfaC/D), type 1 fimbriae (fimH), urinary tract infection (UTI), uropathogenic specific protein (usp), uropathogenic Escherichia coli (UPEC), virulence factors (VFs).

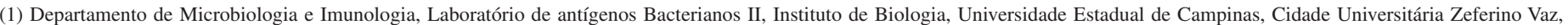
13081-970 Campinas, SP, Brasil.

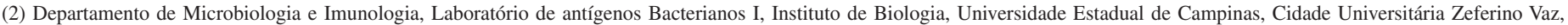
13081-970 Campinas, SP, Brasil.

Correspondence to: Monique Ribeiro Tiba, Phone/Fax: 55.19.3521-6277, 55.19.3521-6272. E-mail: mrtiba@unicamp.br; domingos@unicamp.br 


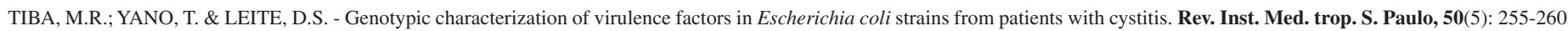
2008 .

Campinas State University (UNICAMP), Campinas, São Paulo. Subjects had no clinical history of severe complications such as vesicoureteral reflux, neurogenic bladder, or malignant neoplasm. The diagnosis of $E$. coli UTI was characterized by typical clinical symptoms of cystitis such dysuria, frequency, urgency, small-volume voids or lower abdominal pain and more than $10^{5} \mathrm{cfu}$ E. coli per $\mathrm{mL}$ urine sample. All isolates were stored at room temperature in NB (Nutrient broth) $0.75 \%$ agar.

The reference E. coli strains FVL2 (sfa, pap, iucD, hly, cnf-1), FV35 ( $a f a, i u c D, c n f-1)$, ORN115 (fimH), FVL8 (sfa, pap, papGII, hly, usp, iucD, cnf1), J96 (papGI and papGIII), U9-41 (O2:K1:H4, kpsMTII), and CLDT7 $(c d t B)$ belong to Laboratório de Antígenos Bacterianos II (Campinas State University) and were used as positive control. E. coli strain DH5 $\alpha$ was used as a negative control.

Polymerase Chain Reaction (PCR): Primers for each VF genes were first established individually by the use of template DNA from appropriate positive and negative control strains. We examined through PCR, the presence of the following groups of genes: colonization factors, such as $\mathrm{P}$ fimbriae ( $p a p C$, papE/F and $p a p G$ alleles), type 1 fimbriae $(f i m H), \mathrm{S}$ fimbriae $(s f a C / D)$, afimbrial adhesin $(a f a B / C)$, group II capsule (kpsMTII), aerobactin (iucD), cytotoxic necrotizing factor type 1 (cnf-1), $\alpha$-hemolysin $(h l y)$, cytolethal distending toxin $(c d t B)$, and uropathogenic specific protein ( $u s p)$. The appropriate primers sequences, annealing temperature, and size of amplified fragment (base pairs - bp) for the characteristics studied are shown in Table 1.

Bacterial DNA to be amplified was released from whole organisms by boiling, and a multiplex PCR assay was carried out in a total volume of $25 \mu \mathrm{L}$, containing $2 \mu \mathrm{L}$ of template DNA, each of the primers at $60 \mathrm{ng}$, the four deoxynucleotide triphosphates (each at $200 \mu \mathrm{M}$ ), PCR buffer 1X and $1.5 \mathrm{U}$ of Taq DNA polymerase ${ }^{3,10}$. For Multiplex PCR, amplifications

Table 1

Characteristics of oligonucleotide sequences used for PCR assays

\begin{tabular}{|c|c|c|c|c|c|}
\hline Genes & Oligonucleotide sequences $\left(5^{\prime} \rightarrow 3^{\prime}\right)$ & Size fragment (bp) & $\begin{array}{l}\text { Concentration of } \\
\text { each primer } \\
(n g / \mu L)\end{array}$ & Reference & $\operatorname{AT}\left(^{\circ}\right)$ \\
\hline cnfl & $\begin{array}{l}\text { CNF1: GAA CTT ATT AAG GAT AGT } \\
\text { CNF2: CAT TAT TTA TAA CGC TG }\end{array}$ & 543 & 90 & 3 & 63 \\
\hline hlyA & $\begin{array}{l}\text { 1: AAC AAG GAT AAG CAC TGT TCT GGC T } \\
\text { 2: ACC ATA TAA GCG GTC ATT CCC GTC A }\end{array}$ & 1,177 & 60 & 27 & 63 \\
\hline papC & $\begin{array}{l}\text { 1:GAC GGC TGT ACT GCA GGG TGT GGC G } \\
\text { 2: ATA TCC TTT CTG CAG GGA TGC AAT A }\end{array}$ & 328 & 60 & 5 & 63 \\
\hline papE/F & $\begin{array}{l}\text { 1:GCA ACA GCA ACG CTG GTT GCA TCA T } \\
\text { 2:AGA GAG AGC CAC TCT TAT ACG GAC A }\end{array}$ & 336 & 60 & 27 & 63 \\
\hline pap G classI & $\begin{array}{l}\text { 1:CAA CCT GCT CTC AAT CTT TAC TG } \\
\text { 2:CAT GGC TGG TTG TTC CTA AAC AT }\end{array}$ & 692 & 60 & 16 & 63 \\
\hline pap G classII & $\begin{array}{l}\text { 1:GGA ATG TGG TGA TTA CTC AAA GG } \\
\text { 2:TCC AGA GAC TGT TCA AGA AGG AC }\end{array}$ & 562 & 60 & 16 & 63 \\
\hline papG classIII & $\begin{array}{l}\text { PG1:CAT GGC TGG TTG TTC CTA AAC AT } \\
\text { PG2:TCC AGA GAC TGT GCA GAA GGA C }\end{array}$ & 421 & 60 & 16 & 63 \\
\hline $\mathrm{fim} H$ & $\begin{array}{l}\text { A: TGC AGA ACG GAT AAG CCG TGG } \\
\text { B GCA GTC ACC TGC CCT CCG GTA }\end{array}$ & 508 & 60 & 11 & 63 \\
\hline$a f a B / C$ & $\begin{array}{l}\text { 1: GCT GGG CAG CAA ACT GAT AAC TCT C } \\
\text { 2: CAT CAA GCT GTT TGT TCG TCC GCC G }\end{array}$ & 750 & 60 & 27 & 63 \\
\hline$s f a D / E$ & $\begin{array}{l}\text { 1: CGG AGG AGT AAT TAC AAA CCT GGC A } \\
\text { 2: CTC CGG AGA ACT GGG TGC ATC TTA C }\end{array}$ & 410 & 90 & 5 & 63 \\
\hline$i u c D$ & $\begin{array}{l}\text { A: TAC CGG ATT GTC ATA TGC AGA CCG T } \\
\text { B:AAT ATC TTC CTC CAG TCC GGA GAA G }\end{array}$ & 602 & 60 & 27 & 63 \\
\hline$c d t B$ & $\begin{array}{l}\text { A: TAT GAT AGC CTC TTT TAT CGT CGT CGT CTG } \\
\text { B: AGA GGA GAG TTA GAG CCT ATG ATA GCC TCT }\end{array}$ & 805 & 60 & This study & 50 \\
\hline usp & $\begin{array}{l}\text { A: ATG CTA CTG TTT CCG GGT AGT GTG T } \\
\text { B: CAT CAT GTA GTC GGG GCG TAA CAA T }\end{array}$ & 1000 & 60 & 24 & 66 \\
\hline kpsMTII & $\begin{array}{l}\text { A: GCG CAT TTG CTG ATA CTG TTG } \\
\text { B: CAT CAG ACG ATA AGC ATG AGC A }\end{array}$ & 272 & 60 & 11 & 63 \\
\hline
\end{tabular}

AT: Annealing Temperature. 


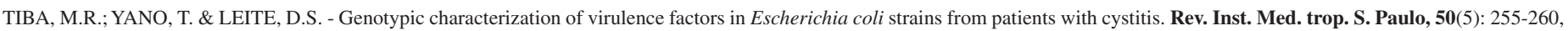
2008 .

consisted of 25 cycles of $94^{\circ} \mathrm{C}$ for one min, specific annealing temperature for each primer for one $\min$ (Table 1 ), $68^{\circ} \mathrm{C}$ for three min, and a final extension at $72{ }^{\circ} \mathrm{C}$ for seven min in a Thermal Cycler (Gene Amp PCR System 9700/Perkin Elmer Corporation, Norwal CT/USA). Primers were then sorted in three pools according to annealing temperature and amplicon size: Multiplex A: papC, papGI, papGII, papGIII; Multiplex B: kpsMTII, papE/F, iucD, hlyA; Multiplex C: $s f a D / E, c n f-1$. The primers for $f i m H, c d t B$, usp and $a f a B / C$ genes were used individually.

The amplified DNA product was visualized by standard submarine gel electrophoresis using $10 \mu \mathrm{L}$ of the final reaction mixture on a $2 \%$ agarose gel in TAE buffer (1,6 M Tris-EDTA, 0,025 M acetic acid). Amplified DNA fragments of specific sizes were located by UV fluorescence, after staining with ethidium bromide. The 100-bp ladder was used as a standard for determining molecular size of PCR products.

\section{RESULTS}

A total of 162 UPEC strains from patients with cystitis were genotypically characterized by the use of PCR assay. The PCR assay results identified $158 \mathrm{fimH}$ (97.5\%), $86 \mathrm{kpsMTII}$ (53.1\%), $53 \mathrm{papC} /$ papEF/papG (32.7\%), 45 sfa (27.8\%), 42 iucD (25.9\%), 41 hly (25.3\%), 36 usp (22.2\%), 30 cnf-1 (18.5\%) and 10 afa (6.2\%) strains (Table 2). All strains were negative for $c d t B$ and $p a p G I$.

A total of 76 strains shared DNA sequences related to, at least, two operons of adhesins, encoding fim $H$ and other genes associated as pap, sfa, and/or afa (Table3).

FimH adhesin was the most prevalent virulence factor detected, having occurred in $97.5 \%$ of strains, and it was detected in $100 \%$ of operon pap (papC/papEF/papG alleles). Eighty two strains of the 158 fim $\mathrm{H}$ studied have only adhesin-encoding operon $\mathrm{fimH}$, and in 48 of them it was not possible to detect any other VF gene.

Among the 53 papC/papE/FpapG strains, 29 were papGII, 23 were papGIII, one was papGII/papGIII and none was papGI (Table 2). Although papG alleles II and III were both associated with $s f a$, they exhibited associations with other VF genes. PapGII allele was associated with iucD, kpsMTII, hly, and negatively associated with $c n f-1$, whereas papG allele III was associated with hly, chf- 1 and kpsMTII. S fimbrial adhesin was associated with $p a p G$ alleles, capsule, cnf-1 and $\alpha$-hly toxins. Table 3 shows the association between virulence factors and adhesins genes.

\section{DISCUSSION}

E. coli is the major causative agent in human UTIs, one of the most common bacterial infections. In most cases, uropathogenic clones are selected from the fecal flora, and the pathogenic potential of E. coli strains is thought to be dependent on the presence of $\mathrm{VFs}^{19,23}$. Based on their components and products called virulence factors, $E$. coli cells attach selectively to the mucosa uro-epithelium, promoting colonization and persisting in the urinary tract, inducing, then, a local inflammatory response and sometimes to promote tissue lesions ${ }^{23,29}$.

We used, to detect and identify the presence of potential uropathogenic Escherichia coli virulence factors, a genotypic assay. PCR method is highly
Table 2

Distribution (number and percentage) of virulence factor genes in uropathogenic E. coli isolates from patients with cystitis

\begin{tabular}{lc}
\hline Virulence factors (genes) & Number of positive strains $(\%)$ \\
\hline fimH & $158(97.5)$ \\
kpsMTII & $86(53.1)$ \\
papC & $53(32.7)$ \\
papE/F & $53(32.7)$ \\
sfaD/E & $45(27.8)$ \\
iucD & $42(25.9)$ \\
hlyA & $41(25.3)$ \\
usp & $36(22.2)$ \\
cnf-1 & $30(18.5)$ \\
papGII & $29(17.9)$ \\
papGIII & $23(14.2)$ \\
afaB/C & $10(6.2)$ \\
papGII/GIII & $1(0.62)$ \\
papGI & $0(0)$ \\
cdtB & $0(0)$ \\
\hline
\end{tabular}

Type 1 fimbriae $(f i m H)$, group II capsule ( $k p s M T I I)$, outer membrane protein of $\mathrm{P}$ fimbrae ( $($ apC $)$, minor structural subunits of $\mathrm{P}$ fimbriae ( $p a p E / F), \mathrm{G}$ adhesin classes of P fimbriae (papG alleles), S fimbriae ( $s f a C / D$ ), aerobactin (iucD), $\alpha$-hemolysin (hly), usp (uropathogenic specific protein), cytotoxic necrotizing factor type 1 (cnf-1), afimbrial adhesin $(a f a B / C)$ and cytolethal distending toxin $(c d B)$.

specific, informative and a powerful genotypic assay, used for detection of adhesin-encoding operons and other virulence factors that can also contribute to virulence in UTI. In this study, we confirmed the prevalence of fimH among UPEC strains ${ }^{10,21,23}$. FimH occurred in 158 strains. Eighty two strains presented only adhesin-encoding operon fim, and in 48 of these strains no other VF gene was detected. This result demonstrated that type 1 fimbriae is an important and relevant VF, and that it can also contribute to virulence in E.coli strains. Type 1-mediated adherence has been proposed to play a role in the induction of inflammation, enhancing $E$. coli virulence for the urinary tract. CONNELL et al., (1996) ${ }^{4}$ reported that mice infected with a type 1-positive $01: \mathrm{K} 1: \mathrm{H} 7$ isolate showed a higher urinary neutrophil influx into the urine than type 1- negative isolates. Furthermore, we demonstrated that 76 fim $H$ strains, occurred with at least one adhesin, such as pap, sfa, or $a f a$. This result corroborates the occurrences presented in the literature, where $f i m H$ was found in associations with P fimbriae and $\mathrm{S}$ fimbriae in $\mathrm{UPEC}^{11}$.

P fimbriae, the principal mannose - resistant adherence organelles of extraintestinal pathogenic Escherichia coli, are known to contribute to pathogenesis by promoting bacterial colonization of host tissues and by stimulating an injurious host inflammatory response $\mathrm{e}^{17}$. E. coli strains were examined for pap genotype and specific primers were utilized to detect genes associated with outer membrane protein (papC), minor structural subunit (papE/F) and papG allele's adhesin (papGI/papGII/ papGIII). 
TIBA, M.R.; YANO, T. \& LEITE, D.S. - Genotypic characterization of virulence factors in Escherichia coli strains from patients with cystitis. Rev. Inst. Med. trop. S. Paulo, 50(5): 255-260, 2008 .

Table 3

Association between virulence factors and adhesins genes of uropathogenic E. coli isolates from patients with cystitis

\begin{tabular}{|c|c|c|c|c|c|c|c|c|c|c|c|c|c|c|c|c|c|c|c|c|c|c|c|c|c|}
\hline Genes & $\lesssim$ & ज्ञ & 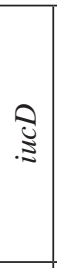 & $\frac{2}{2}$ & స्ञे & $\begin{array}{l}\tilde{\Xi} \\
\frac{\tilde{Z}}{0} \\
\stackrel{\Xi}{\Xi}\end{array}$ & 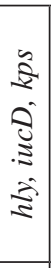 & 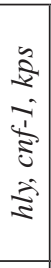 & 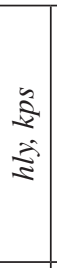 & $\begin{array}{l}\frac{\tilde{z}}{2} \\
\frac{-}{5} \\
\frac{5}{5}\end{array}$ & 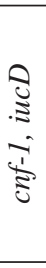 & 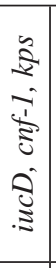 & 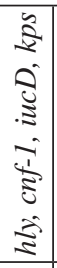 & $\begin{array}{l}3 \\
\frac{2}{3} \\
3\end{array}$ & $\begin{array}{l}T \\
\frac{1}{5} \\
5 \\
5 \\
3\end{array}$ & $\begin{array}{l}\frac{2}{2} \\
\frac{2}{3} \\
3\end{array}$ & 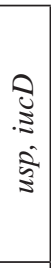 & 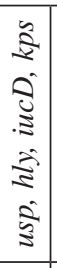 & $\begin{array}{l}\frac{\tilde{2}}{2} \\
\frac{3}{2} \\
\frac{\hat{2}}{3}\end{array}$ & 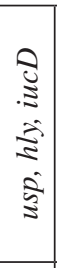 & 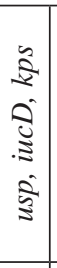 & 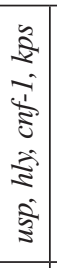 & 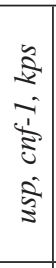 & 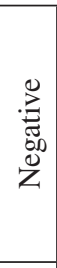 & 㫯 \\
\hline $\mathrm{fimH}$ & & & 6 & 10 & 5 & 5 & & & 2 & & & & & 1 & & 4 & 1 & & & & & & & 48 & 82 \\
\hline fimH/papC/EF/GII & & & & 1 & & 5 & 3 & & & & & & & & & 1 & & & & & 2 & & & 3 & 15 \\
\hline fimH/papC/EF/GIII & & & & & & & & 2 & 3 & & & & & & & & & & 1 & 1 & & 1 & & & 7 \\
\hline fimH/papC/EF/GII/sfa & & & & & & 1 & 4 & & & 1 & & & & & & 1 & & 3 & & & & & & 1 & 12 \\
\hline fimH/papC/EF/GIII/sfa & 1 & & & 1 & & & & 4 & & 3 & & & 1 & & & & & & 1 & & 1 & 4 & & & 16 \\
\hline fimH/papC/papGII/afa & & & & & & & 1 & & & & & & & & & & & & & & & & & 1 & 2 \\
\hline fimH/sfa & & 1 & & & & & & 1 & & 5 & 1 & & 1 & & 1 & 1 & & 1 & & & & 2 & 1 & & 15 \\
\hline$s f a$ & 1 & & & & & & & & & & & & & & & & & & & & & & & & 1 \\
\hline fimH/afa & & & & 2 & 1 & 1 & & & & & & & & & & & & & & & 1 & & & 2 & 7 \\
\hline fimH/sfalafa & & & & & & & & & & & & 1 & & & & & & & & & & & & & 1 \\
\hline fimH/papC/EF/GII/GIII & & & & & & & & & & & & & & 1 & & & & & & & & & & & 1 \\
\hline Negative & & & & 1 & & 1 & 1 & & & & & & & & & & & & & & & & & & 3 \\
\hline Total & 2 & 1 & 6 & 15 & 6 & 13 & 9 & 7 & 5 & 9 & 1 & 1 & 2 & 2 & 1 & 7 & 1 & 4 & 2 & 1 & 4 & 7 & 1 & 55 & 162 \\
\hline
\end{tabular}

Type 1 fimbriae $(f i m H)$, group II capsule ( $k p s M T I I)$, outer membrane protein of P fimbrae (papC), minor structural subunits of $\mathrm{P}$ fimbriae (papE/F), G adhesin classes of P fimbriae (papG alleles), S fimbriae ( $s f a C / D)$, aerobactin (iucD), $\alpha$-hemolysin ( $h l y)$, uropathogenic specific protein (usp), cytotoxic necrotizing factor type 1 ( $c n f$ 1), afimbrial adhesin $(a f a B / C)$.

The classes of $p a p G$ genotype differed according to the type of receptor specificity and infection ${ }^{22,23}$. The class II $\mathrm{G}$ adhesin is associated with pyelonephritis and bacteremia, while the class III G adhesin sequence is associated with cystitis, although they have been found in pyelonephritis and bacteremia ${ }^{6,9}$. PapGI strains might have a larger prevalence among fecal isolates.

Fifty three strains $(32.7 \%$ ) were papC/papE/F/papG, demonstrating the presence of the intact operon, responsible for adhesin assembly. This frequency of pap in a cystitis strain agrees with literature data ${ }^{26}$. JOHNSON et al., $2005^{11}$, reported that cystitis isolates differed from pyelonephritis and prostatitis isolates by their lower prevalence of papA/C/EF/G, pap G allele II and the papGII/III alleles combination. We found 53 strains papC and all of them presented papG, demonstrated by PCR. There were 29 papGII strains, 23 papGIII strains and one strain carrying both sequences. The result that papGIII was less prevalent than papGII was not expected, since the strains were all derived from patients with cystitis.

PapGII and papGIII alleles are found in association with $h l y^{2} . E$. coli strains that produce Hly, frequently produce other two urovirulent factors: CNF-1 and P fimbriae. These three genes are found in the same pathogenicity island (PAI) ${ }^{2,10}$. In this study we detected 1 papGII/GIII/ hly strain, 11 papGII/hly strains and 19 papGIII/hly strains. Our results are similar to that described in the literature ${ }^{2}$, where the hemolytic gene $(h l y A)$ is present in both pap $G$ alleles.
While $h l y$ was found in association with $\mathrm{P}$ fimbriae, $c n f l$ was detected in $27 s f a$ strains. This result corroborates the occurrences presented in literature where, $c n f-1$ was found in association with $s f a^{10,23}$.

Cdt-producing $E$. coli strains were first isolated from children with enteritis ${ }^{12}$. In other studies, $c d t$ genes were detected in urosepsis and fecal E. coli isolates and from patients with a variety of diarrhea symptoms and encephalopathy ${ }^{10,13}$. CDTs produce giant mononucleated cells caused by an irreversible block in the cell cycle at the G2/M, occurring cellular death. In this study, $c d t B$ was not detected by the PCR assay, indicating their relative unimportance in our E.coli collection. This finding suggests that cystitis can be caused by strains that are less virulent than those isolates that had $c d t B$ and typically cause pyelonephritis, urosepsis and diarrhea.

Other VF found in association with pyelonephritis, meningitis and sepsis is $\mathrm{S}$ fimbriae ${ }^{23}$. S fimbrial adhesin recognizes surface sialic acid content, on receptors expressed by kidney epithelial and vascular endothelial cells, mediating bacterial adherence. Recently, it was identified sialic acid residues in the UP3, one of the four integral membrane uroplakin proteins, expressed on the bladder luminal surface, suggesting that $\mathrm{S}$ fimbriae may also have a role in cystitis ${ }^{20}$. We detected $45 s f a$ strains. Sfa was found in positive cnf-1, hly and papG alleles strains (Table 3). These results were similar to the ones described in the literature ${ }^{2,10}$.

The concentration of iron $(\mathrm{Fe})$ is limited in sites of extraintestinal 


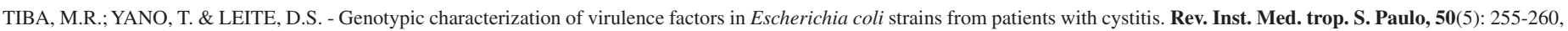
2008

infection, in large part, due to host factors that reduce its availability. As a result, $\mathrm{Fe}$ acquisition is of critical need for pathogens that must grow within a host. One of the iron acquisition mechanisms is the biosynthesis of siderophore ${ }^{7}$. In the literature was reported that aerobactin system was found associated with papG allele $\mathrm{II}^{2}$. In this study, we detected 19 papGII/iucD strains and three papGIII/iucD strains, then, these results were similar to the ones described in the literature 2 .

The majority of the UPEC strains present group II capsules (K1, K5) determined by kps operon ${ }^{8}$. Capsule is common in UPEC and is better known for contributing with pyelonephritis than other urinary tract infections ${ }^{8}$. In this study were detected $86(53.1 \%)$ kpsMTII strains. All of them were associated with other VF searched. The literature reported the association among the VFs present in UPEC: capsule, papG allele II and aerobactin. An association of kpsMTII and $h l y A$ was also observed. Our results corroborate those present in the literature ${ }^{10}$, once we found 19 papGII/kps/iucD strains and only two papGIII/kps/iucD strains.

KURAZONO et al. $(2000)^{18}$ reported a putative pathogenicity island (PAI), which was more frequently found in UTI collections than in fecal E. coli. This PAI contains usp that encodes a 346-amino acid protein, which was designated as uropathogenic specific protein (usp). PARRET \& DE MOT $(2002)^{25}$ hypothesized that the usp protein may represent a novel type of $E$. coli bacteriocin, acting against competing E. coli strains that occupy the same niche, thereby enhancing their infectivity in the urinary tract environment. Recently, it was demonstrated that usp significantly enhanced the infectivity of $E$. coli in the mouse UTI model ${ }^{29}$.

In the study proceeding from Japan, usp gene occurred in $80 \%$ of 195 cystitis isolates, and $93 \%$ of the 76 pyelonephritis isolates ${ }^{18}$. It was noted that $u s p$ occurred more frequently in pyelonephritis than cystitis ${ }^{14}$. Herein, we detected 36 usp (22.2\%) strains, and the reason for differences between these studies could be interpreted as being due to distinct women population analyzed or from the existence of different bacterial clones distributed between women from Brazil and Japan.

The VFs displayed distinctive and complex associations with each other. We demonstrated that $p a p G$ allele II was found in positive $k p s$, $i u c D$ and hly strains and was not found in positive $c n f l$ strain, whereas pap $G$ allele III was associated with kps, hly and $c n f-1$ genes. Both papG alleles were associated with $\mathrm{S}$ fimbriae. S fimbriae were positively associated with cnf- 1 and $h l y, k p s M T I I$ and papG alleles.

The present study provides molecular epidemiological information about VF genes found in lower UTI (cystitis). We have rigorously established a multiplex PCR assay, capable of detecting VF highly prevalent among UTI isolates. We confirmed the prevalence of fimH genes among $E$. coli strains from cystitis. We showed that $\mathrm{P}$ and type 1 fimbriae are not sole adhesins on uropathogenic E. coli and that these adhesions, may be multiple within a single strain with several virulence genes occurring together in association.

\section{RESUMO}

\section{Caracterização genotípica dos fatores de virulência em amostras de Escherichia coli isoladas de pacientes com cistite}

Adesinas (Fímbria P, fímbria S, fímbria do tipo 1 e a adesina afimbrial), toxinas ( $\alpha$-hemolisina e o fator necrosante citotóxico do tipo 1 ), sistemas de captação de ferro (aerobactina), e mecanismos de defesa do hospedeiro (cápsula ou lipopolissacarídeo) são prevalentes em amostras de Escherichia coli associadas a infecções do trato urinário. O objetivo deste trabalho foi caracterizar genotipicamente 162 amostras de Escherichia coli uropatogênica (UPEC) de pacientes com cistite através do ensaio da reação em cadeia da polimerase. Foram realizados três ensaios de PCR multiplex para os seguintes fatores de virulência: $p a p C$, $p a p E / F$, alelos de $p a p G$, fim $H$, sfalfoc, afaE, hly, cnf-1, usp, cdtB, iucD, e kpsMTII. Os resultados da PCR identificaram, 158 amostras fimH (97,5\%), 86 amostras $k p s M T I I(53,1 \%)$, 53 amostras papC/papEF/papG (32,7\%), 45 amostras sfa (27,8\%), 42 amostras $i u c D(25,9 \%), 41$ amostras $h l y(25,3 \%), 36$ amostras usp (22,2\%), 30 amostras cnf-1 (18,5\%) e 10 amostras afa $(6,2 \%)$. Nenhuma amostra foi positiva para o gene $c d t B$. Neste trabalho, demonstramos que podemos encontrar múltiplas adesinas em uma única amostra e que diferentes genes de fatores de virulência podem ser encontrados em associação.

\section{ACKNOWLEDGMENTS}

We are grateful to Mr. Erivaldo José da Silva and Mrs Mirtis Ferraz for technical support. This work was supported by Coordenação de Aperfeiçoamento de Pessoal de Nível Superior (CAPES).

\section{REFERENCES}

1. ARISOY, M.; AYSEV, D.; EKIM, M. et al. - Detection of virulence factors of Escherichia coli from children by multiplex polymerase chain reaction. Int. J. clin. Pract., 60: 170-173, 2006.

2. BINGEN-BIDOIS, M.; CLERMONT, O.; BONACORSI, S. et al. - Phylogenetic analysis and prevalence of urosepsis strains of Escherichia coli bearing pathogenicity islandlike domains. Infect. Immun., 70: 3216-3226, 2002.

3. BLANCO, M.; BLANCO, J.E.; ALONSO, M.P. et al. - Detection of pap, sfa and afa adhesinencoding operons in uropathogenic Escherichia coli strains: relationship with expression of adhesins and production of toxins. Res. Microbiol., 148: 745-755, 1997.

4. CONNELL, H.; AGACE, W.; KLEMM, P. et al. - Type 1 fimbrial expression enhances Escherichia coli virulence for the urinary tract. Proc. nat. Acad. Sci. (Wash.), 93: 9827-9832, 1996

5. DAIGLE, F.; HAREL, J.; FAIRBROTHER, J.M \& LEBEL, P. - Expression and detection of pap, sfa, and $a f a$ - encoded fimbrial adhesin systems among uropathogenic Escherichia coli. Clin. J. Microbiol., 40: 286-291, 1994.

6. FÉRIA, C.; MACHADO, J.; DUARTE-CORREIA, J.; GONÇALVES, J. \& GAASTRA, W. - Distribution of pap $G$ alleles among uropathogenic Escherichia coli isolated from different species. FEMS Microbiol. Lett., 202: 205-208, 2001.

7. GRIFFITHS, E. - Iron and the virulence of Escherichia coli. In: SUSSMAN, M. Escherichia coli mechanisms of virulence. Cambridge, Cambridge University Press, 1997. p. 331-371.

8. JANN, K. \& JANN, B. - Capsules of Escherichia coli. In: SUSSMAN, M. Escherichia coli mechanisms of virulence. Cambridge, Cambridge University Press, 1997. p. 113-142.

9. JOHNSON, J.R.; RUSSO, T.A.; BROWN, J.J. \& STAPLETON, A. - papG alleles of Escherichia coli strains causing first episode or recurrent cystitis in adult women. J. infect. Dis., 177: 97-101, 1998

10. JOHNSON, J.R. \& STELL, A.L. - Extended virulence genotypes of Escherichia coli strains from patients with urosepsis in relation to phylogeny and host compromise. J. infect. Dis., 181: 261-272, 2000. 
TIBA, M.R.; YANO, T. \& LEITE, D.S. - Genotypic characterization of virulence factors in Escherichia coli strains from patients with cystitis. Rev. Inst. Med. trop. S. Paulo, 50(5): 255-260, 2008.

11. JOHNSON, J.R.; KUSKOWSKI, M.A.; GAJEWSKI, A. et al. - Extended virulence genotypes and phylogenetic background of Escherichia coli isolates from patients with cystitis, pyelonephritis, or prostatitis. J. infect. Dis., 191: 46-50, 2005

12. JOHNSON, W.M. \& LIOR, H. - A new heat-labile cytolethal distending toxin (CLDT) produced by Escherichia coli isolates from clinical material. Microb. Pathog., 4: 103-113, 1988 .

13. KADHUM, H.J.; FINLAY, D.; ROWE, M.T.; WILSON, I.G. \& BALL, H.J. - Occurrence and characteristics of cytotoxic necrotizing factors, cytolethal distending toxins and other virulence factors in Escherichia coli from human blood and faecal samples. Epidem. Infect., 136: 752-760, 2008

14. KANAMARU, S.; KURAZONO, H.; ISHITOYA, S. et al. - Distribution and genetic association of putative uropathogenic virulence factors iroN, iha, kpsMT, ompT and usp in Escherichia coli isolated from urinary tract infections in Japan. J. Urol., 170: 2490-2493, 2003.

15. KANAMARU, S; KURAZONO, H; NAKANO, M. et al. - Subtyping of uropathogenic Escherichia coli according to the pathogenicity island encoding uropathogenicspecific protein: comparison with phylogenetic groups. Int. J. Urol., 13: 754-760, 2006.

16. KARKKAINEN, U.M.; KAUPPINEN, J.; IKAHEIMO, R.; KATILA, M.L. \& SIITONEN, A. - Rapid and specific detection of three different $\mathrm{G}$ adhesin classes of P-fimbriae in uropathogenic Escherichia coli by polymerase chain reaction. J. microl. biol. Method., 34: 23-29, 1998

17. KUEHN, M.J.; JACOB-DUBUISSON, F.; DODSON, K. et al. - Genetic, biochemical, and structural studies of biogenesis of adhesive pili in bacteria. Meth. Enzym., 236: 282-306, 1994

18. KURAZONO, H.; YAMAMOTO, S.; NAKANO, M. et al. - Characterization of a putative virulence island in the chromosome of uropathogenic Escherichia coli possessing a gene encoding a uropathogenic-specific protein. Microb. Pathog., 28:183-189, 2000.

19. LANE, M.C.; SIMMS, A.N. \& MOBLEY, H.L. - Complex interplay between type 1 fimbrial expression and flagellum-mediated motility of uropathogenic Escherichia coli. J. Bact., 189: 5523-5533, 2007.
20. MALAGOLINI, N.; CAVALLONE, D.; WU, X.R. \& SERAFÍN-CESSI, F. - Terminal glycosylation of bovine uroplakin III, one of the major integral-membrane glycoproteins of mammalian bladder. Biochim. Biophys. Acta, 1475: 231-237, 2000

21. MORIN, M.D. \& HOPKINS, W.J. - Identification of virulence genes in uropathogenic Escherichia coli by multiplex polymerase chain reaction and their association with infectivity in mice. Urology, 60: 537-541, 2002.

22. MULVEY, M.A.; SCHILLING, J.D.; MARTINEZ, J.J. \& HULTGREN, S. - Bad bug and beleaguered bladders: interplay between uropathogenic Escherichia coli and innate host defenses. Proc. nat. Acad. Sci. (Wash.), 97: 8829-8835, 2000.

23. MULVEY, M.A. - Adhesion and entry of uropathogenic Escherichia coli. Cell. Microbiol., 4: $257-271,2002$.

24. NAKANO, M.; YAMAMOTO, S.; TERAI, A. et al. - Structural and sequence diversity of the pathogenicity island of uropathogenic Escherichia coli which encodes the USP protein. FEMS Microbiol. Lett., 205: 71-76, 2001.

25. PARRET, A.H. \& DE MOT, R. - Escherichia coli's uropathogenic-specific protein: a bacteriocin promoting infectivity? Microbiology, 148: 1604-1606, 2002.

26. SANTO, E.; MACEDO, C. \& MARIN, J.M. - Virulence factors of uropathogenic Escherichia coli from a university hospital in Ribeirão Preto, São Paulo, Brazil. Rev. Inst. Med. trop. S. Paulo, 48: 185-188, 2006.

27. YAMAMOTO, S.; TERAI, A., YURI, K. et al. - Detection of urovirulence factor in Escherichia coli by multiplex polymerase chain reaction. FEMS Immunol. med. Microbiol., 12: 85-90, 1995.

28. YAMAMOTO, S.; NAKANO, M.; TERAI, A. et al. - The presence of the virulence island containing the $u s p$ gene in uropathogenic Escherichia coli is associated with urinary tract infection in an experimental mouse model. J. Urol., 165: 1347-1351, 2001.

29. YAMAMOTO, S. - Molecular epidemiology of uropathogenic Escherichia coli. J. Infect. Chemother., 13: 68-73, 2007.

Received: 3 March 2008

Accepted: 6 August 2008 